\title{
Esclerite como Manifestação Inicial de Granulomatose de Wegener: Descrição de Caso
}

\section{Wegener's Granulomatosis Presenting as Scleritis: Case Report}

\author{
Leonardo Schmidt ${ }^{(1)}$, Claudine J. C. Burkiewicz ${ }^{(1)}$, Marilia Barreto Silva $^{(2)}$, Thelma L. Skare ${ }^{(2)}$
}

\section{RESUMO}

Esclerite é um processo inflamatório ocular caracterizado por edema e infiltração celular da esclera, que cursa com vermelhidão e dor locais e causa perda importante da acuidade visual. Pode ser a primeira manifestação de uma doença reumática sistêmica como lúpus, artrite reumatóide e policondrite recidivante, embora seja mais comum que apareça bastante tempo depois da doença já estabelecida. Os autores apresentam um caso de granulomatose de Wegener no qual essa forma de envolvimento ocular precedeu o aparecimento de glomerulonefrite em 18 meses.

Palavras-chave: granulomatose de Wegener, esclerite, glomerulonefrite.

\section{INTRODUÇÃO}

Esclerite é um processo inflamatório ocular que pode trazer graves prejuízos à visão ${ }^{(1)}$. Em grande parte dos casos, o processo é puramente ocular, mas, em cerca de $50 \%$ deles, existe uma doença sistêmica que deve ser reconhecida e tra$\operatorname{tada}^{(1)}$. Em $30 \%$ dos casos, essa doença é a artrite reumatóide, sendo os outros $20 \%$ causados por granulomatose de Wegener (GW), poliarterite nodosa, lúpus, síndrome de Goodpasture, policondrite recidivante, herpes zoster, sífilis etc. ${ }^{(1)}$. Quando a forma da esclerite é grave, como é o caso das necrotizantes, a chance de associação com uma doença sistêmica aumenta, podendo chegar de $75 \%$ a $80 \%$ dos $\operatorname{casos}^{(2)}$.

Nas esclerites, o olho funciona como um verdadeiro termômetro do processo inflamatório sistêmico, servindo ao reumatologista como um guia para a agressividade do tratamento a ser indicado. Isso fica muito claro em casos de artrite reumatóide, em que é fato reconhecido que doentes com esclerite têm um prognóstico pior, inclusive com diminuição de sobrevida(3).

De maneira reversa, o prognóstico ocular também está intimamente ligado à doença sistêmica de fundo. Segundo

\begin{abstract}
Scleritis is an ocular inflammatory condition characterized by edema and cellular infiltration of the sclera that causes local redness, pain and loss of visual acuity. It can be the first manifestation of a systemic rheumatic disease such as lupus, rheumatoid arthritis and relapsing polycondritis, although it is more frequently found in a well established disease. The authors describe a case of Wegener's granulomatosis where this form of ocular involvement preceded the glomerulonephritis by eighteen months.
\end{abstract}

Keywords: Wegener's granulomatosis, scleritis and glomerulonephritis.

De La Maza et $a l^{(2)}$, as esclerites associadas com lúpus são as mais benignas, ao passo que as associadas com GW são as que mais causam cegueira. As da artrite reumatóide e da policondrite recidivante têm um prognóstico intermediário.

Além da doença sistêmica de fundo, o tipo de esclerite influi no prognóstico ocular. A forma anterior difusa é a com menor incidência de perda visual, sendo a de melhor prognóstico; a nodular tem um prognóstico intermediário e a forma necrotizante é a que mais freqüentemente acarreta perda visual $^{(4)}$.

Os autores descrevem um caso de esclerite anterior necrotizante causada por GW que apareceu 18 meses antes das manifestações sistêmicas da doença, ilustrando a associação das doenças reumatológicas com essa forma de envolvimento ocular.

\section{DESCRIÇÃO DE CASO}

Homem de 43 anos, técnico agrícola, é encaminhado ao Serviço de Oftalmologia do Hospital Universitário Evangélico de Curitiba para investigação de esclerite necrotizante em olho esquerdo. 
Contava história de poliartrite e febre há dois anos, tratada alhures com antiinflamatórios não-hormonais. Esses sintomas duraram cerca de um mês e desapareceram mesmo após a suspensão dos medicamentos. Tinha, também, uma história de fístula anal que estava em acompanhamento pelo ambulatório de Clínica Cirúrgica e, segundo o paciente, tinha feito uma investigação com enema opaco e colonoscopia que teriam sido normais (sic). Para essa fístula tinha usado apenas tratamento local. Além disso, havia sido tratado de otite há cerca de um ano. Não existiam antecedentes de mastoidites, sinusites ou pneumopatias. Um irmão mais jovem tinha diagnóstico de artrite reumatóide, mas o paciente desconhecia detalhes de sua doença.

No momento da consulta, negava história de aftas, fotossensibilidade, dor articular, erupções cutâneas, distúrbios de ritmo intestinal, problemas respiratórios, doenças renais e cefaléia.

O exame físico foi normal exceto pelos achados oculares (Figura 1).

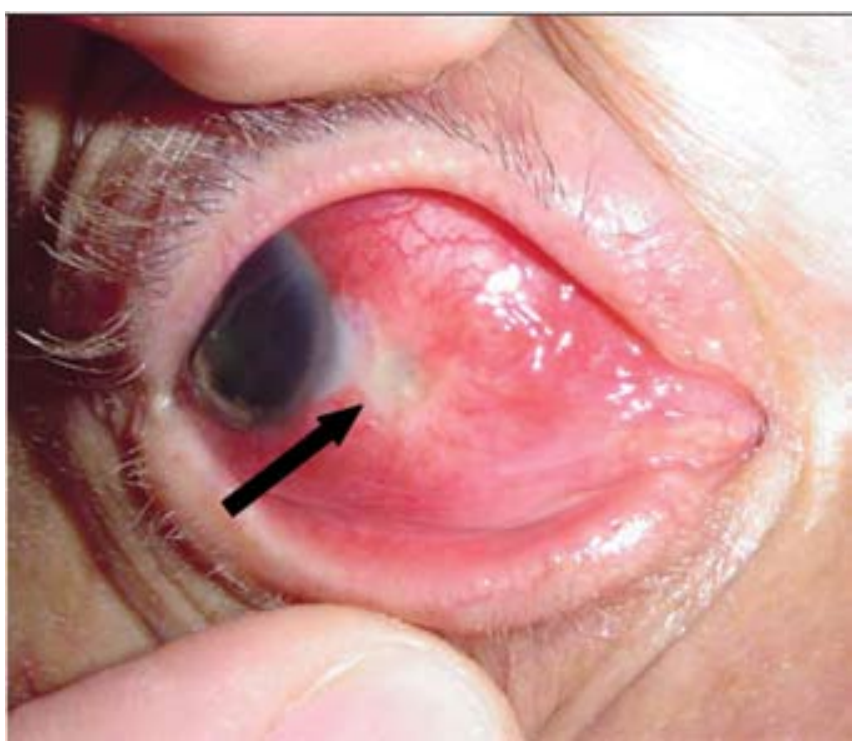

Figura 1 - Esclerite. A flecha aponta para área de necrose avascular (branca).

Os exames mostraram: hemograma e parcial de urina normais, VHS $=9 \mathrm{~mm}$ na $\mathrm{l}^{\mathrm{a}} \mathrm{h}$; FAN e FR negativos; creatinina de $0,89 \mathrm{mg} / \mathrm{ml}$; TAC de tórax e RX de seios da face foram normais. Um Anca-c foi positivo no título de $1 / 640$.

Com diagnóstico de granulomatose de Wegener - forma limitada, foi tratado com corticóide em doses altas ( $1 \mathrm{mg} / \mathrm{kg} /$ dia de prednisona) que foi, progressivamente, sendo diminuído, seguido por azatioprina (150 mg/dia).
Em consulta, quatro meses após a instituição dessa forma de tratamento, observou-se melhora do quadro ocular, sendo possível retirar a prednisona.

Dezoito meses depois da consulta inicial, quando compareceu para controle, afirmou que havia abandonado o uso de azatioprina por sentir-se bem. Não apresentava queixas e o exame físico era normal, exceto pela pressão arterial de $160 \times 100 \mathrm{mmHg}$ e seqüelas do envolvimento escleral.

Nessa ocasião, seus exames mostravam uma creatinina de $1,5 \mathrm{mg} \%$ e um parcial de urina com 12.000 hemácias $/ \mathrm{mm}^{3}$ com cilindros hialinos. Um clearance de creatinina foi de $102 \mathrm{ml} / \mathrm{min}$ e proteinúria de 24 horas de $507 \mathrm{mg}$. Nova tomografia de tórax foi normal. Foi, então, submetido à biópsia de rim que mostrou glomerulonefrite necrotizante segmentar sem depósitos de complexo imunes a imunofluorescência. Instituiu-se terapêutica com ciclofosfamida oral $(2 \mathrm{mg} / \mathrm{kg} /$ dia) e prednisona ( $1 \mathrm{mg} / \mathrm{kg} / \mathrm{dia})$ com normalização da creatinina $(0,9 \mathrm{mg} \%)$ e parcial de urina normal.

Atualmente, o paciente encontra-se bem - tendo sido retirada a prednisona - em uso apenas da ciclofosfamida oral.

\section{DISCUSSÃO}

O diagnóstico de GW é facilmente realizado nos casos clássicos, em que o paciente se apresenta em sua tríade característica: comprometimento de vias aéreas superiores, inferiores e rim. Entretanto, existem situações em que a forma da doença é localizada, exigindo para o seu reconhecimento um alto grau de suspeita por parte do clínico.

Casos isolados de envolvimento de meninges ${ }^{(5,6)}$, massas intracranianas e renais ${ }^{(7,8)}$, otites ${ }^{(8)}$ e massas em topografia mamária ${ }^{(9)}$ e submandibular ${ }^{(10)}$ têm sido descritos entre outros. Quando a GW se apresenta de maneira isolada, mas são encontrados achados histológicos condizentes com esse diagnóstico, diz-se que esta é uma forma limitada ou parcial e sabe-se que tal forma tende a cursar com testes negativos para a pesquisa do Anca ${ }^{(6)}$.

O envolvimento ocular na forma de esclerite, como visto no quadro inicial do paciente descrito, é, talvez, uma das formas localizadas mais reconhecidas na literatura. Outras formas de comprometimento ocular da GW incluem ceratites (inclusive as ulcerativas periféricas), episclerites, oclusão de vasos centrais da retina, conjuntivite crônica, envolvimento orbitário causando proptose, vasculites retinianas e granulomas na conjuntiva ${ }^{(11)}$.

Um estudo de Harper et al $^{\left({ }^{(1)}\right)}$, envolvendo 47 pacientes de GW com esclerite, observou a existência de quatro tipos de processo evolutivo: 
1. pacientes nos quais a doença sistêmica aparece antes do diagnóstico ocular ( $57,4 \%$ das situações);

2. pacientes em que a doença ocular antecede o envolvimento sistêmico $(6,4 \%$ dos casos);

3. pacientes com doença sistêmica e ocular de aparecimento simultâneo $(6,4 \%)$;

4. pacientes nos quais existe exclusivamente a doença ocular. Alguns autores têm proposto, para esta última opção, o nome de doença muito limitada ou compartimentalizada, embora a aceitação desta denominação não seja unânime ${ }^{(5)}$.

A GW é, geralmente, uma doença grave e potencialmente fatal. Um diagnóstico precoce seguido de um tratamento adequado pode ser benéfico e deve ser perseguido com insistência. $\mathrm{O}$ uso de ciclofosfamida e de corticóide em altas doses tem sido feito com sucesso, porém à custa de

\section{REFERÊNCIAS}

1. Rao NA, Marak GE, Hidayat AA: Necrotizing scleritis: A clinicopathologic study of 41 cases. J Ophthalmology 92: 1542-9, 1985.

2. De La Maza MS, Foster S, Jabbur NS: Scleritis associated with systemic vasculitis diseases. Ophtalmology 102: 687-92, 1995.

3. Foster CS, Forstot SL, Wilson LA: Mortality rate in rheumatoid arthritis patients developing necrotizing scleritis or peripheral ulcerative keratitis. J Ophtalmology 91: 1253-63, 1984.

4. Tuft SJ, Watson PG: Progression of scleral disease. Ophtalmology 98: 467-71, 1991.

5. Specks U, Moder KG, McDonald TJ: Meningeal involvement in Wegener Granulomatosis. Mayo Clin Proc 75: 856-9, 2000.

6. Newman NJ, Slamovits TL, Friedland S, Wilson WB: Neuroophtalmic manifestations of meningocerebral inflammation from the limited form of Wegener Granulomatosis. Am J Ophthalmol 120: 613-21, 1995. sérios efeitos colaterais. Como as formas limitadas da doença tendem a seguir um curso um pouco mais indolente e benigno (porém sujeito a recidivas) ${ }^{(6)}$, cria-se um impasse para a escolha terapêutica, principalmente da ciclofosfamida.

No caso descrito, optou-se inicialmente pelo uso do corticóide e da azatioprina, além de uma cuidadosa vigilância. Tais medicamentos conseguiram regressão do processo inflamatório ocular. Todavia, a vigilância proposta foi burlada pelo próprio paciente, que suspendeu o uso da azatioprina. Não se sabe se esta teria ou não conseguido evitar o aparecimento do comprometimento renal. Entretanto, essa possível falha foi prontamente corrigida pelo acompanhamento mantido, instituindo-se a ciclofosfamida assim que o comprometimento renal foi detectado.

Declaramos a inexistência de conflitos de interesse.

7. Carazo ER, Benitez AM, Milena GL, Espigares JR, Leon L, Márquez B: Multiple renal masses as initial manifestation of Wegener Granulomatosis. Am J Radiol 176: 116-8, 2001.

8. Helmberger R, Mancuso A: Wegener granulomatosis of Eustachian tube and skull base mimicking malignant tumor. Am J Neuroradiol 17: 1785-90, 1996.

9. Deininger HK: Wegener granulomatosis of the breast. Radiology 154: 59-60, 1985.

10. Garcia-Porrua C, Amor-Dorado JC, Gonzalez-Gay MA: Unilateral submandibular swelling as unique presentation of Wegener's granulomatosis. Rheumatology 40: 953-4, 2001.

11. Harper SL, Letko E, Michael C, et al: Wegener's granulomatosis: the relantionship between ocular and systemic disease. J Rheumatol 28: 1025-32, 2001. 